Review

\title{
Designing Impactful Construction Safety Training Interventions
}

\author{
Lynal Albert * and Camren Routh
}

Citation: Albert, L.; Routh, C. Designing Impactful Construction Safety Training Interventions. Safety 2021, 7, 42. https://doi.org/ $10.3390 /$ safety7020042

Academic Editors: Adel Badri and Raphael Grzebieta

Received: 4 March 2021

Accepted: 14 May 2021

Published: 20 May 2021

Publisher's Note: MDPI stays neutral with regard to jurisdictional claims in published maps and institutional affiliations.

Copyright: (c) 2021 by the authors. Licensee MDPI, Basel, Switzerland. This article is an open access article distributed under the terms and conditions of the Creative Commons Attribution (CC BY) license (https:/ / creativecommons.org/licenses/by/ $4.0 /)$.
Department of Engineering and Computer Science, School of Engineering, Tarleton State University, Stephenville, TX 76402, USA; camren.routh@gmail.com

* Correspondence: albert@tarleton.edu; Tel.: +1-254-968-9727

\begin{abstract}
Construction workplaces still report an unacceptable number of safety incidents every year. To tackle these disproportionate incident rates, safety training interventions are adopted widely in construction workplaces. Despite their adoption, poor safety performance continues to be a universal and global problem in the industry. In fact, recent research has called into question the effectiveness of training programs that are commonly adopted in the industry. There is also evidence that suggests that training interventions, in many cases, do not yield tangible benefits and may sometimes simply reduce to wasted resources. Therefore, it is important for industry stakeholders to possess a good understanding of the characteristics of training interventions that translate to superior safety performance. Towards achieving this goal, the present article concisely summarizes specific safety training intervention elements, which when integrated into training programs, can translate into superior safety performance and outcomes. The objectives of the research were achieved by performing a review of the construction safety training literature from diverse sources. The findings demonstrate that training interventions that integrate visual cues to guide hazard recognition, immersive experiences in virtual environments, andragogical training principles, personalization of training experiences, testing and feedback, and other elements can improve training effectiveness and outcomes. The article will serve as a resource for industry professionals that seek to address the weaknesses of existing training interventions. Researchers may also use this as a resource to inform the development of the next generation of safety training interventions. Together, the presented research can be leveraged to reduce the number of undesirable safety incidents experienced in construction workplaces.
\end{abstract}

Keywords: construction safety; safety training; safety intervention; occupational safety and health; safety management; hazard training

\section{Background}

Construction workplaces report a disproportionate number of workplace injuries every year [1]. For example, in the United States, more than $20 \%$ of work-related fatal incidents are experienced in construction workplaces [2]. In the same manner, the construction industry is among the industries that report the highest number of injuries that result in disabilities, days away from work, and those that require immediate medical attention [3]. Accordingly, construction workers are disproportionately more likely to be injured than workers in most other industries [4]. Apart from the suffering and pain that are directly associated with these incidents, these injuries result in several other undesirable outcomes. For example, the cost of these injuries, which include worker compensation, medical treatment, penalties, and other expenses, exceeds millions of dollars each year in the United States [5]. In addition, loss of reputation, legal challenges, and project failures are all more likely when workplace injuries are experienced in workplaces [6].

Because of the significance of the undesirable outcomes discussed above, a considerable amount of effort has been devoted to injury prevention. These include establishing 
and enforcing safety regulations, conducting regular drug testing, and introducing policies that require frequent safety inspections [7-9]. Apart from such efforts, another form of intervention that is common in construction workplaces is the administering of safety training programs [10-16]. These training efforts focus on ensuring that field workers are proficient in identifying and managing safety issues in construction workplaces to prevent any workplace accident or safety incident $[17,18]$.

Unfortunately, there is a large body of research that argues that safety training efforts in practice have not yielded sufficient benefits for a variety of reasons [18]. For example, there is evidence to suggest that employers sometimes prioritize productivity and cost-savings over offering the best training interventions. This is particularly an issue in the construction industry given the temporal nature of construction operations, the transient nature of the workforce, and the fear that well-trained workers are often attracted by competing businesses [19]. Other challenges to the adoption of effective training interventions include factors such as time constraints in construction projects, disinterest among fellow workers, and the lack of clarity on how training translates to tangible benefits [17].

Despite the various barriers to the adoption of effective training practices discussed above, and given that the cost of injuries and the penalties associated with poor safety performance has considerably increased in the last decades, employers are increasingly being incentivized to invest in safety training programs [20]. Accordingly, employers are taking a more active role in offering safety training interventions to their workforce $[21,22]$.

However, poor training practices are widespread in the construction industry $[12,15,16,21]$. The adoption of these poor training practices often diminishes the returns or even negates the potential benefits that can potentially be achieved if effective training interventions are adopted. For example, past research has demonstrated that the most common approach to training construction workers involves the use of lecture-based, classroom-type instructional methods that do not elicit interest or sufficiently engage workers $[12,15,16,21]$. Unfortunately, the adoption of such unengaging training methods can lead workers to form a negative attitude towards safety training programs, which can translate to apathy and poor safety performance $[16,23]$.

Therefore, employers and relevant industry stakeholders need to be aware of training program elements that will sufficiently engage workers and translate to desirable training outcomes-such as superior safety performance. As a step towards making this knowledge available to these stakeholders, the objective of the presented review article was to examine the broad and fragmented literature on construction safety training and distill the key elements that are known to render safety training programs to become effective. The findings can be used by industry stakeholders as a resource to develop and design robust safety training programs that will translate into superior safety performance in construction workplaces.

\section{Methods}

To unveil the key elements that are associated with impactful training interventions, a comprehensive review of the construction safety literature was targeted. Prior to the initiation of the review effort, the selection and exclusion criteria, potential sources of information, planned search strategy, and the screening process for the relevant articles were outlined as per the recommended practices for such investigations [24].

With regards to the selection criteria, the review scope was limited to articles published in the last 20 years. This limited scope was targeted to ensure that the state-of-the-art training elements are captured and that the findings can be leveraged as actionable knowledge for the design of new and novel safety training interventions. Efforts that focused on safety but did not explicitly discuss construction safety training interventions were not targeted. Other efforts that focused on safety training but did not discuss specific safety training elements were also not included in the selection criteria (i.e., efforts that focused on assessing the attitude of workers towards safety training in general). In addition, only articles that were in English were targeted as part of the research effort. 
As a starting point, broad searches were conducted on databases including Scopus, Web of Science, Google Scholar, and the American Society of Civil Engineers (ASCE) library to identify relevant articles as per the predefined potential sources of information. Search terms that were used as per the planned search strategy included safety training, construction safety training, hazard training, safety interventions, and safety management. The resulting articles were reexamined to identify articles that specifically discussed safety training elements that improve training outcomes by reviewing the title and the abstract in accordance with the planned screening process. When the relevance of particular articles was unclear from the review of the title and the abstracts, the other sections of the article were reviewed by the authors to assess relevance. All articles that offered evidence of the effectiveness of particular safety training elements were included as part of the effort. Overall, over 80 articles were found to fit the criteria of the study.

Next, each of the articles were examined and specific safety training elements were extracted and cataloged. Given that the articles explicitly identified the training elements of interest, a manual process was sufficient for the extraction process. As the examination progressed, the training elements identified were cataloged on a spreadsheet on an on-going basis and combined with existing ones whenever found to be necessary [25]. Once the set of unique training elements were cataloged successfully, a reexamination of the relevant articles was performed to extract the key benefits offered by each of the safety training elements. Identifying the benefits offered the necessary context for the purposes of the currently reported study. These benefits were identified and organized as subthemes that were linked to each of the safety elements that served as the themes in the spreadsheet manually.

\section{Findings}

The research resulted in the identification of safety training elements that are known to improve the outcomes of safety training interventions. For this article, the findings are presented under 19 categories. It should be noted that the safety training elements that were identified were not necessarily mutually exclusive. Therefore, the purpose of the distinctions that are made between the elements as presented in the next section is simply to present the results in a logical and coherent manner for easy consumption for readers.

\subsection{Visual Cues, Mental Schemas, and Energy-Based Mnemonics}

Among other things, construction workers are required to examine workplaces and recognize and manage safety hazards that can cause harm [26]. However, in most cases, construction workers do not particularly adopt any systematic approach to guide their hazard recognition process [15]. In most cases, workers simply adopt an unstructured approach where they haphazardly scan the work environment with the hope that the hazards that can cause harm will automatically capture their attention [27,28]. Unfortunately, recent research demonstrates that such an unstructured approach for recognizing safety hazards can lead to superficial and suboptimal performance $[29,30]$. For example, in many cases, where a systematic process is not adopted, workers largely only capture and report generic hazards, such as fall potential, trip likelihood, pinch-points, etc., irrespective of the work context or the operations that are planned for execution [31]. Moreover, in such cases, workers are likely to fail to recognize other hazards that are relevant and can cause injury [31]. When such unrecognized hazards are present in the workplace, workplace injuries become more likely since unrecognized hazards are also likely to remain unmanaged [15].

One of the systematic approaches that have been suggested and successfully incorporated as part of training efforts is the provision of visual cues, mental schemas, or energy-based mnemonics to guide the hazard recognition process $[10,15,32]$. The visual cues that are offered to workers as part of the training are based on Haddon's energy release theory, which suggests that any undesirable exposure to an energy source can lead to injuries or accidents $[10,29,33]$. 
As part of intervention elements, workers are provided with 10 energy sources as visual cues that they can use to guide their hazard recognition efforts in workplaces $[10,15,32]$. The energy sources that are included as part of the training efforts include gravity to prompt workers to identify hazards, such as leading edges, slippery surfaces, and falling objects; motion that trigger the recognition of hazards, such as moving equipment, vehicles, and objects; and electrical to promote the recognition of hazards from energized equipment, power lines, and power outlets; etc. The ten energy sources that are part of the intervention elements are presented in Figure 1.

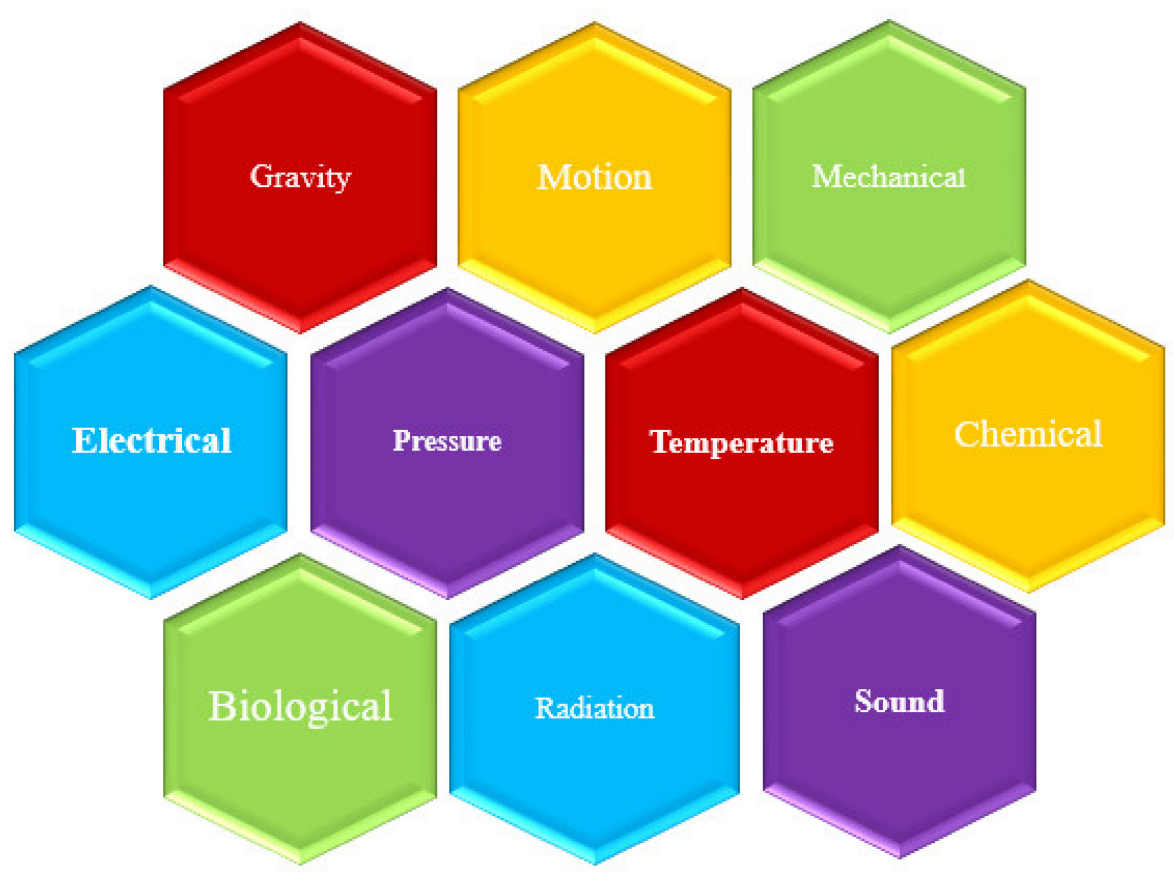

Figure 1. Schematic representation of visual cues, mental schemas, and energy-based mnemonics.

\subsection{Training in Virtual Reality/Augmented Reality/Immersive Environments}

Given the safety risks of offering training in actual workplaces, a large body of research has successfully leveraged virtual environments, augmented reality, 360 videos, and immersive environments to offer robust training for workers $[10,34,35]$. The primary advantage of these environments is to simulate dangerous workplace conditions that are necessary as part of the training that cannot be replicated in real workplaces due to the safety risks [36]. While virtual environments allow the simulation of hypothetical situations, 360 videos can capture actual workplace conditions-both of which are associated with complementary advantages [34]. Past research has also demonstrated that immersive environments have also been able to engage and immerse workers into training experiences that translate into superior training outcomes [10].

\subsection{Multimedia Presentations including Animations, Videos, and Photographs}

A large number of training efforts adopt multimedia sources to communicate important safety information. For example, videos and animations that recreate previously experienced incidents are common [37-39]. Moreover, the communication of safety regulations and best practices are efficiently achieved by these multimedia sources $[40,41]$. The primary benefit of using these multimedia presentations is the superior engagement that is achieved [37]. In addition, given that the recordings, videos, and animations can be reused, this form of training offers a cost-effective means for training [39]. These multimedia resources are increasingly being integrated as part of online education and training to reach a broad audience [38]. 


\subsection{Testing and Feedback}

A number of training interventions have successfully incorporated testing and feedback $[14,15,42]$. In these training programs, the skill level of the trainees is first assessed to identify and demonstrate the need for training [15]. Once the trainee perceives this need for training, feedback is offered based on the trainees' initial performance to demonstrate areas for improvement or to clarify performance expectations $[17,43,44]$. Such testing along with feedback has been demonstrated to enhance hazard recognition skill, reduce risk-taking behavior, and result in desirable safety-related behaviors [15,43].

\subsection{Leveraging Eye-Tracking Technology and Visual Attention Maps}

A number of recent studies have leveraged the power of eye-tracking technology and visual attention maps to enhance the hazard recognition ability of workers [45-47]. More specifically, these efforts have largely tasked workers or individuals examine construction workplaces or images of workplaces to identify safety hazards. Once the hazard recognition effort of a trainee is completed, a visual attention map that highlights hazards that received attention and those that did not receive attention is highlighted to workers or the individuals $[15,45]$. Moreover, these visual attention maps also reveal problem areas that need to be addressed using training. Using eye-tracking technology along with the visual attention maps to offer feedback and training to workers has been demonstrated to improve the effectiveness of hazard recognition training interventions [15].

\subsection{Metacognitive Prompts}

Metacognition is a self-introspection process through which an individual examines their own mental processes to identify weaknesses that will need attention [48,49]. Metacognitive prompts are prompts that elicit or assist individuals to become aware of weaknesses in their own thinking or mental processes [50,51]. Accordingly, metacognitive prompts have been used to assist workers to self-evaluate the reasons why they fail to recognize hazardous conditions either in a training setting or in the workplace. For example, past research has tasked workers to recognize safety issues in a work setting [15]. Next, feedback is offered on the hazards that they failed to recognize during the activity along with metacognitive prompts to foster self-evaluation [15]. Examples of metacognitive prompts that have been used include asking workers if they failed to recognize a particular safety hazard because they were unable to see it visually (e.g., poisonous gases, buried power lines), if they were not familiar with the task that was associated with the recognized hazard (e.g., stud welding), or if they perceived the hazard to impose relatively low levels of safety risk [52]. A total of 13 metacognitive prompts can be found in Jeelani et al. [15].

\subsection{Hierarchy of Controls}

The hierarchy of controls [53] that was introduced by the National Safety Council in 1950 and later recognized by the National Institute for Occupational Safety and Health (NIOSH) has been successfully embedded in many safety training programs $[34,54]$. The hierarchy of controls is a simple and schematic representation of safety control measure categories that are organized in accordance with their relative effectiveness, as shown in Figure 2. 


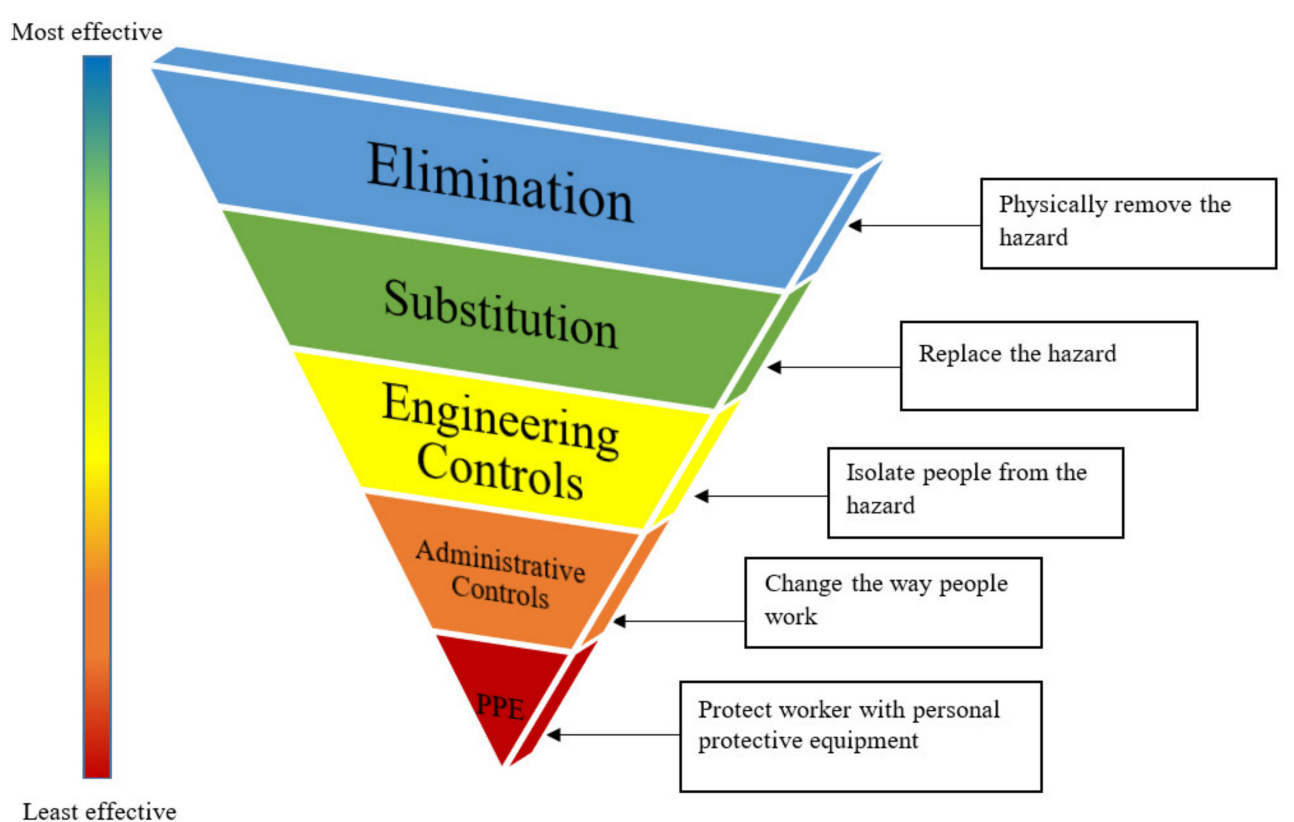

Figure 2. Schematic representation of the Hierarchy of Controls [53].

As can be seen, the hierarchy of controls suggests that the most effective approach to control safety hazards is to eliminate the hazard. An example of elimination would be to adopt a design that eliminates the risk of fall from heights by adopting a novel design that does not require work from height (e.g., precast elements constructed on the ground level in a controlled environment). However, given that the design development is significantly upstream to construction operations, they are often more difficult to adopt and more expensive in practice given existing barriers in the industry [53]. In contrast, the least effective safety control measure is the reliance on personal protective equipment (PPE), which may be less reliable in preventing an injury. In fact, PPE has often been labeled as the least effective safety control measure. The schematic, as presented in Figure 2, is often integrated into training programs to assist workers and other stakeholders prioritize and adopt feasible safety controls that are the most effective in preventing workplace injuries [34,54].

\subsection{Hands-On and Active Training Approaches}

Much of the safety training efforts that are adopted in the construction industry are passive in nature; i.e., where the trainer presents information in a classroom-type setting while the trainees are only required to be passively attentive $[11,21,55,56]$. Unfortunately, there is a large body of research that demonstrates that such training approaches do not yield desirable levels of return $[16,57,58]$. Accordingly, a large body of research has advocated for the use of hands-on and active modes of training where the trainees play a more central and active role $[16,59,60]$. Examples of active training methods include role-playing, work-together groups, brainstorming, and participation in simulated virtual environments, and the use of physical models to demonstrate safety concepts $[12,56,61]$.

\subsection{On-the-Job Training and Apprenticeship Programs}

A significant body of literature advocates for the adoption of on-the-job training and apprenticeship programs for training purposes [19,39,62]. According to this literature, offering on-the-job training and apprenticeship programs provide the necessary context for the work, which results in the training being more relevant to daily work operations $[61,63]$. Moreover, there is evidence to suggest that on-the-job training results in the development of skills that workers are more likely to replicate after the conclusion of the training efforts when they return to the workplace $[64,65]$. There are also discussions in the literature that argues that on-the-job training offers a more realistic and immersive 
environment when compared to other training formats [64]. Much of the on-the-job training efforts and apprenticeship programs are also hands-on in nature, which offer additional benefits $[12,16,21]$. The one downside of on-the-job training and apprenticeship programs is the close proximity to real safety hazards in a workplace setting, which can increase the risk of injury [36].

\subsection{Integration of Training Transfer Elements}

One of the largest challenges associated with safety training is that workers that receive training do not necessarily apply the concepts learned when they return back to work $[13,18,66,67]$. Therefore, much of the training efforts do not yield desirable levels. To ensure that that the learning gained from training is applied when workers return to the field, past research has suggested that training transfer elements must be embedded $[18,68]$. Examples of training transfer elements include implementation tools such as checklists, booklets, and pocket cards that workers can use at the work interface that are built upon the training material that was offered. The training experience should also be designed to be sufficiently vivid and be representative of real construction operations to facilitate training transfer $[69,70]$. Apart from designing the training experience and the associated implementation resources, findings suggest that other elements, such as supervisor expectation, commitment from the upper management, peer support and reinforcement, and the placement of appropriate incentives, foster the transfer of training [18].

\subsection{Andragogy-Based Training}

Much of the training offered in the industry largely adopts a pedagogical instructional approach. However, an emerging body of literature argues that these pedagogical training approaches are more appropriate for school-aged children and must be replaced with andragogical approaches that are more suitable for adult learners $[12,21,55,71]$. This body of literature argues that unlike a pedagogical approach where the instructor plays a more authoritarian role in a classroom-like setting, andragogical training approaches recognize trainees as collaborators that possess useful and relevant experiences that can serve as a resource during training efforts [55,72]. Accordingly, the trainer plays the role of a facilitator in the andragogical approach rather than an instructor, which is typical of pedagogical training approaches. In addition, given the relevant experience that trainees bring, trainees play a more active role as part of the training experience in andragogical approaches as opposed to being more passive and dependent on the instructor as is the case in pedagogical training approaches [72]. For example, the trainees share the rich experience they possess and learn in a collaborative and conducive environment.

\subsection{Naturalistic Injury Simulations and Physical Demonstrations}

An emerging body of research has focused on developing physical and naturalistic simulations that demonstrate previously experienced real-life workplace injuries using hyper realistic replicas of human body parts and common construction tools that can cause injuries during training demonstrations. For example, past research has leveraged physical demonstrations where a concrete chisel is dropped on a human hand replica [11,12]. The findings demonstrated that the adoption of these physical naturalistic injury simulations yields an emotional response among trainees [12]. These emotional responses in turn translate to superior learning and risk aversion, which are fundamental to discourage risktaking behavior in construction workplaces. Other efforts have used physical dummies to represent realistic incidents involving pieces of equipment, construction material, and tools to demonstrate safety risks and appropriate safety measures in a range of activities, which include excavation operations, work in proximity to powerlines, and lifting and hoisting $[73,74]$. Training efforts that focus on educating workers on the proper use of personal protective equipment (PPE) and equipment operation are also common [40]. 


\subsection{Serious Games and Gamification of Safety Training}

The application of gaming concepts to foster learning has garnered much interest in the safety training literature [10,75-77]. The literature suggests that the integration of gaming concepts, such as a goal or challenge, specific rules that are to be followed, and virtual or physical rewards as progress in the training is achieved, can improve training outcomes $[10,78,79]$. Moreover, such serious games-based training interventions can increase engagement, motivation, and learning [80]. Much of these serious games use a virtual training platform where a trainee can move through a 3D space and interact with virtual objects such as hazards, personal protective equipment, equipment, and other elements while trying to achieve their training goals [10]. However, the concept of gamification can also be applied to training in a physical or a classroom-type environment [81].

\subsection{Personalized and Adaptive Training}

Most of the training interventions, whether offered in a classroom-type setting or a virtual environment, adopts a one-size-fits-all training approach [15]. These training interventions do not consider the specific learning needs or weaknesses of particular trainees. While these training efforts can be useful, a few efforts have advocated for the personalization of training interventions $[15,82,83]$. These interventions are designed to examine the learning needs of individuals and adapt or personalize the learning experience in accordance with the observed weaknesses or training needs of the trainees $[17,83]$. The literature on the personalization of training argues that such a training approach ensures that resources are used efficiently to target specific learning needs while also reducing inattention, frustration, and boredom among the training participants [15]. Moreover, such a training approach avoids repetitive and unnecessary instruction when workers are already proficient in specific safety competency areas [15].

Apart from personalizing training to specific worker needs, others have advocated designing training programs in accordance with the culture, educational background, and the learning preference (e.g., language) of groups or communities of workers [84,85].

\subsection{E-Learning or Online-Based Safety Training}

E-learning or online-based safety training interventions have been demonstrated to be particularly useful when a large number of trainees or workers are to be trained [36, $61,85,86]$. In these circumstances, such training efforts have been shown to translate into much cost and time savings [85]. Other benefits of this form of training that is discussed in the literature include the ability to save training progress, access to the training material through any internet-connected device, and the ability to repeat the training experienceon-demand-as and when needed at the preferred location for the workers [85]. Such forms of training interventions were also found to be useful when a face-to-face mode of training was not feasibly particularly in the context of the currently experienced COVID-19 pandemic [87]. Moreover, there is much research that suggests that online-based safety training offered over mobile devices will particularly be impactful among younger and future construction workers and professionals [88].

\subsection{Focus-Four Hazards Training}

Past efforts have unveiled that the most common causes of fatalities in construction workplaces include falls, struck-by incidents, caught-in/between incidents, and electrical incidents [1]. More specifically, these incident categories account for more than $70 \%$ of the fatalities experienced in the construction industry. To address this industry-wide issue, the Occupational Safety and Health Administration (OSHA) developed training programs that targeted these incident types-which were labeled as the focus-four hazards as shown in Figure 3 [89]. In addition, the training material was made freely and publicly available to industry stakeholders to incorporate as part of their own training efforts [20]. Consequently, the focus-four hazards have been incorporated in much of the training programs across the industry, including the widely popular OSHA 10-h construction training outreach 
program $[20,90,91]$. Given its widespread use, a number of research efforts have tested and validated the usefulness of these training programs that highlight the focus-four hazards [20,91,92].

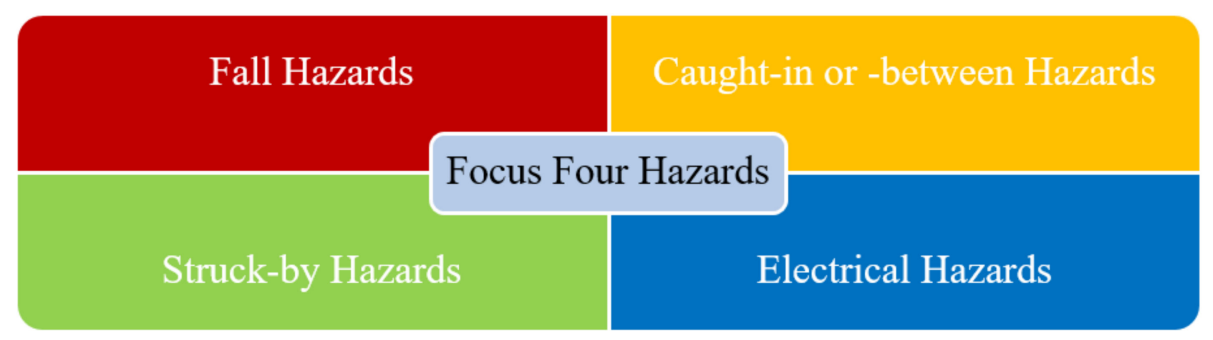

Figure 3. Schematic representation of the focus-four hazards.

\subsection{Peer-Led or Initiated Training}

Peer-led training has been discussed in the literature as offering many benefits $[93,94]$. For example, there is evidence that workers trust their peers more over their employers and are more responsive to the training coordinated and offered by their peers [93,94]. This is particularly the case among immigrant workers that are known to experience employerinitiated abuses, such as non-payment and overtime threats, and higher levels of community hostility [62]. In addition, there is much literature to support that these peer-led efforts foster cohesion, community, and collaborative learning among peers, which facilitates the transfer of the training to the workplace following the training experience [62,94-96].

\subsection{Practice-Based Training and Guided Practice Sessions}

As discussed earlier, much of the safety training is offered in a classroom-like setting using a lecture-based approach $[12,16,21]$. However, training efforts that allow participants to practice through trial and error, whether in a real environment with adequate protection or in a virtual environment, can foster skills development $[15,97,98]$. Moreover, guided practice sessions, where a seasoned or experienced instructor or coworker coaches the trainee as the trainee practices specific skills, can also promote learning as the mental processes adopted by the experienced instructor or coworker becomes more apparent to the trainee worker [34]. For example, guided workplace inspections as part of the training have been identified as being useful to trainees to identify work-related safety issues [34].

\subsection{Social and Collaborative Learning Experiences}

Evidence from the literature demonstrates that social learning approaches are powerful mechanisms through which workers learn $[22,60,99]$. According to this body of literature, embedding workers or trainees in a community of peers that value and prioritize safety will result in the workers or trainees themselves adopting the desirable safety behaviors $[100,101]$. Such a form of learning occurs because it is natural for humans to observe, interact, and emulate the behavior of their peers or the community they are embedded in [101,102]. For example, workers that are placed in crews or workplaces that maintain a positive safety climate have been shown to demonstrate superior safety skills as a result of social or collaborative learning mechanisms [100,101].

\section{Discussions, Limitations, and Future Suggested Research}

As presented in the above section, a variety of training program elements have been adopted to enhance the training experience of workers and the training outcomes experienced. The safety training elements along with the key benefits are summarized succinctly in Table 1. These safety training elements can be strategically adopted to design more impactful training programs that yield larger benefits. For example, industry leaders and employers can integrate particular training intervention elements discussed above to strengthen their current training programs. These stakeholders can also integrate a combination of the presented elements to achieve larger impacts and address the limitations 
associated with specific training elements. For example, the hierarchy of control safety training element discussed in the article could be communicated to workers using multimedia presentations that include relevant animation, videos, and photographs of relevant workplace safety controls. Such training efforts can empower workers with the necessary skills that are needed for their own safety and the safety of their peers. Such efforts can also translate into superior safety performance where fewer injuries, disabilities, days away from work, and medical case incidents are reported from construction workplaces. A unified approach where the industry adopts such safety training elements can address the much-needed improvement in safety that the industry has been seeking for decades.

Table 1. Summary of safety training elements along with key benefits.

\begin{tabular}{|c|c|}
\hline Safety Training Elements & Key Benefits \\
\hline $\begin{array}{l}\text { Visual Cues, Mental Schemas, and } \\
\text { Energy-Based Mnemonics }\end{array}$ & $\begin{array}{l}\text {-Guides workers to systematically examine workplaces to enhance hazard } \\
\text { recognition levels }\end{array}$ \\
\hline $\begin{array}{l}\text { Training in Virtual Reality/Augmented } \\
\text { Reality/Immersive Environments }\end{array}$ & $\begin{array}{l}\text {-Offers a safe environment for demonstrating high-risk workplace conditions that } \\
\text { cannot be replicated in real workplaces } \\
\text {-Associated with high engagement levels and immersive experiences }\end{array}$ \\
\hline $\begin{array}{l}\text { Multimedia Presentations including } \\
\text { Animations, Videos, and Photographs }\end{array}$ & $\begin{array}{l}\text {-Developed resources can be reused in a cost-effective manner } \\
\text {-Is being integrated into online education and training modules that are widely } \\
\text { distributed }\end{array}$ \\
\hline & -Useful in packaging essential safety information in an engaging manner \\
\hline Testing and Feedback & -Evaluate current skill level and offers clarity on what good performance looks like \\
\hline Leveraging Eye-Tracking Technology and & -Highlights weaknesses associated with hazard recognition abilities \\
\hline Visual Attention Maps & -Offers the capability of providing feedback and self-assessment \\
\hline Metacognitive Prompts & $\begin{array}{l}\text {-Guides trainees to self-assess weaknesses and adopt remedial efforts } \\
\text {-Simple schematic representation of safety control measures }\end{array}$ \\
\hline Hierarchy of Controls & $\begin{array}{l}\text {-Guides trainees to prioritize safety control measures based on relative } \\
\text { effectiveness to minimize safety risks }\end{array}$ \\
\hline Hands-on and Active Training Approaches & -Associated with superior engagement levels and training outcomes \\
\hline On-the-job Training and Apprenticeship & -Offers suitable context and realistic environment for training activities \\
\hline programs & -Trainees are more likely to replicate learned concepts at the workplace \\
\hline Integration of Training Transfer Elements & -Ensures that learned concepts from training are adopted in the workplace \\
\hline Andragogy-based Training & -Better suited for adult workers and promotes collaborative learning \\
\hline $\begin{array}{l}\text { Naturalistic Injury Simulations and Physical } \\
\text { Demonstrations }\end{array}$ & $\begin{array}{l}\text {-Offers the capability of communicating safety information in a realistic and } \\
\text { tangible manner }\end{array}$ \\
\hline $\begin{array}{l}\text { Serious Games and Gamification of Safety } \\
\text { Training }\end{array}$ & -Promotes learning using an engaging experience \\
\hline Personalized and Adaptive Training & $\begin{array}{l}\text {-Tailors learning experiences in accordance to the training needs of trainees } \\
\text {-Eliminates repetitive and unnecessary training in areas trainees are already } \\
\text { proficient }\end{array}$ \\
\hline E-learning or Online-based Safety Training & $\begin{array}{l}\text {-Offers the ability to train large number of trainees in a cost-effective manner } \\
\text {-Trainees may be able to access training material on an on-demand basis }\end{array}$ \\
\hline Focus-Four Hazards Training & $\begin{array}{l}\text {-Targets safety hazards that are responsible for a disproportionate number of } \\
\text { fatalities effectively }\end{array}$ \\
\hline Peer-led or Initiated Training & -Empower trainees to learn from each other in a friendly and safe setting \\
\hline $\begin{array}{l}\text { Practice-based training and Guided practice } \\
\text { sessions }\end{array}$ & -Allows trainees to learn safety information using a trial and error approach \\
\hline $\begin{array}{l}\text { Social and Collaborative Learning } \\
\text { Experiences }\end{array}$ & motes mutual learning through observations, interaction, and emulation. \\
\hline
\end{tabular}

Although the presented research only examines safety training intervention in the context of the construction industry, the findings are expected to be useful and relevant to other high-risk occupational settings, including mining, agriculture, and healthcare. In addition, the findings will be useful in other contexts where training is relevant, such as in education, medicine, and other professional and non-professional settings.

While the study findings offer important and useful information, there are few limitations that will need to be addressed in future research. For example, while the intervention elements that are presented are known to enhance the training outcomes, there is less 
clarity on the relative impacts of the individual elements due to a number of reasons. First, there is significant variability in the reported benefits that were observed when the same intervention elements were adopted across the different studies and settings whenever relevant. Second, a large number of studies did not control for external factors, such as the support offered by the employer, the safety culture maintained by the site leadership, and the characteristics of the workers themselves when assessing the relative benefits achieved. Third, several of the studies adopted multiple training elements that are discussed above, and isolating the effects of these individual training elements is not possible from the study results. Finally, while several studies demonstrated that the adoption of the training elements translated into many benefits, a comparison of the relative effects is challenging since the outcomes that were measured across the studies are very variable. For example, a few studies examined the effects of the intervention elements on safety behaviors. Others examined the effect of the training elements on hazard recognition skill, safety risk perception, the self-reported satisfaction of the trainees at the conclusion of the training, injury rates, and others.

Future studies may tackle some of the above-discussed limitations by adopting empirical investigations that can examine the questions that remain unanswered. The findings from such follow-up efforts can empower industry stakeholders with the ability to design more impactful training programs that translate into superior training outcomes and lower injury rates. Future research can also examine the literature outside the construction industry domain to identify and test intervention elements that have been successfully adopted in other contexts and industries. Moreover, efforts can also examine if particular training elements are more appropriate for specific training outcomes (e.g., risk tolerance). Finally, the effect of combining various training elements on training outcomes will also be useful in understanding interactions and the incremental improvements that can be achieved.

\section{Conclusions}

Unacceptable injury rates continue to be a major challenge in the construction industry [1]. One of the solutions that is proposed in a large body of research is the adoption of safety training programs to enhance the competency of workers in managing workplace safety [10-16]. Unfortunately, existing and widely adopted training interventions have not yielded sufficient improvements [17,18]. With the increasing cost of workplace injuries and the unacceptable distress experienced among workers following workplace incidents, efforts that focus on enhancing safety training programs that can yield tangible benefits are fundamental.

The current effort examined the broader construction safety literature to identify training program elements that have been known to enhance safety training outcomes. Overall, the effort unveiled 19 training elements. Examples of training elements include integrating visual cues, mental schemas, and energy-based mnemonics; training in virtual reality/augmented reality/immersive environments; multimedia presentations, including animations, videos, and photographs; and others. Industry stakeholders can integrate these training elements to design more impactful safety training experiences for their workers. Such efforts to improve the effectiveness of training program interventions can translate into superior safety performance.

Author Contributions: L.A. developed the study plan and took the lead role in writing the article; C.R. led the literature review effort and the compilation of findings. All authors have read and agreed to the published version of the manuscript.

Funding: This research received no external funding.

Data Availability Statement: The data are available upon request.

Conflicts of Interest: The authors declare no conflict of interest. 


\section{References}

1. Occupational Safety and Health Administration. Commonly Used Statistics. Available online: https://www.bls.gov/iif/oshcfoi1 .htm (accessed on 22 January 2021).

2. Bureau of Labor Statistics (BLS). Census of Fatal Occupational Injuries (CFOI). Available online: https://www.bls.gov/iif/ oshcfoi1.htm (accessed on 22 January 2021).

3. Bureau of Labor Statistics (BLS). Injuries, Illnesses, and Fatalities. Available online: https://www.bls.gov/iif/ (accessed on 22 January 2021).

4. Dong, X.; Platner, J.W. Occupational Fatalities of Hispanic Construction Workers from 1992 to 2000. Am. J. Ind. Med. 2004, 45, 45-54. [CrossRef] [PubMed]

5. Waehrer, G.M.; Dong, X.S.; Miller, T.; Haile, E.; Men, Y. Costs of Occupational Injuries in Construction in the United States. Accid. Anal. Prev. 2007, 39, 1258-1266. [CrossRef]

6. Zou, P. Strategic Safety Management in Construction and Engineering; Wiley: Hoboken, NJ, USA, 2015.

7. Lehtola, M.M.; van der Molen, H.F.; Lappalainen, J.; Hoonakker, P.L.; Hsiao, H.; Haslam, R.A.; Hale, A.R.; Verbeek, J.H. The Effectiveness of Interventions for Preventing Injuries in the Construction Industry: A Systematic Review. Am. J. Prev. Med. 2008, 35, 77-85. [CrossRef] [PubMed]

8. Subramani, T.; Lordsonmillar, R. Safety Management Analysis in Construction Industry. Int. J. Eng. Res. Appl. 2014, 4, 117-120.

9. Minchin, R.E., Jr.; Glagola, C.R.; Guo, K.; Languell, J.L. Case for Drug Testing of Construction Workers. J. Manag. Eng. 2006, 22, 43-50. [CrossRef]

10. Albert, A.; Hallowell, M.R.; Kleiner, B.; Chen, A.; Golparvar-Fard, M. Enhancing Construction Hazard Recognition with High-Fidelity Augmented Virtuality. J. Constr. Eng. Manag. 2014, 140, 04014024. [CrossRef]

11. Bhandari, S.; Hallowell, M.R. Emotional Engagement in Safety Training: Impact of Naturalistic Injury Simulations on the Emotional State of Construction Workers. J. Constr. Eng. Manag. 2017, 143, 04017090. [CrossRef]

12. Bhandari, S.; Hallowell, M.R.; Correll, J. Making Construction Safety Training Interesting: A Field-Based Quasi-Experiment to Test the Relationship between Emotional Arousal and Situational Interest among Adult Learners. Saf. Sci. 2019, 117, 58-70. [CrossRef]

13. Burke, L.A.; Hutchins, H.M. Training Transfer: An Integrative Literature Review. Hum. Resour. Dev. Rev. 2007, 6, 263-296. [CrossRef]

14. Demirkesen, S.; Arditi, D. Construction Safety Personnel's Perceptions of Safety Training Practices. Int. J. Proj. Manag. 2015, 33, 1160-1169. [CrossRef]

15. Jeelani, I.; Albert, A.; Azevedo, R.; Jaselskis, E.J. Development and Testing of a Personalized Hazard-Recognition Training Intervention. J. Constr. Eng. Manag. 2017, 143, 04016120. [CrossRef]

16. Namian, M.; Albert, A.; Zuluaga, C.M.; Behm, M. Role of Safety Training: Impact on Hazard Recognition and Safety Risk Perception. J. Constr. Eng. Manag. 2016, 142, 04016073. [CrossRef]

17. Jeelani, I.; Albert, A.; Han, K.; Azevedo, R. Are Visual Search Patterns Predictive of Hazard Recognition Performance? Empirical Investigation using Eye-Tracking Technology. J. Constr. Eng. Manag. 2019, 145, 04018115. [CrossRef]

18. Namian, M.; Albert, A.; Zuluaga, C.M.; Jaselskis, E.J. Improving Hazard-Recognition Performance and Safety Training Outcomes: Integrating Strategies for Training Transfer. J. Constr. Eng. Manag. 2016, 142, 04016048. [CrossRef]

19. Wang, Y.; Goodrum, P.M.; Haas, C.T.; Glover, R.W. Craft Training Issues in American Industrial and Commercial Construction. J. Constr. Eng. Manag. 2008, 134, 795-803. [CrossRef]

20. Albert, A.; Pandit, B.; Patil, Y. Focus on the Fatal-Four: Implications for Construction Hazard Recognition. Saf. Sci. 2020, 128, 104774. [CrossRef]

21. Wilkins, J.R. Construction Workers' Perceptions of Health and Safety Training Programmes. Constr. Manag. Econ. 2011, 29, 1017-1026. [CrossRef]

22. Le, Q.T.; Lee, D.Y.; Park, C.S. A Social Network System for Sharing Construction Safety and Health Knowledge. Autom. Constr. 2014, 46, 30-37. [CrossRef]

23. Haslam, R.A.; Hide, S.A.; Gibb, A.G.; Gyi, D.E.; Pavitt, T.; Atkinson, S.; Duff, A.R. Contributing Factors in Construction Accidents. Appl. Ergon. 2005, 36, 401-415. [CrossRef]

24. Moher, D.; Shamseer, L.; Clarke, M.; Ghersi, D.; Liberati, A.; Petticrew, M.; Shekelle, P.; Stewart, L.A. Preferred Reporting Items for Systematic Review and Meta-Analysis Protocols (PRISMA-P) 2015 Statement. Syst. Rev. 2015, 4, 1-9. [CrossRef]

25. Saldaña, J. The Coding Manual for Qualitative Researchers; Sage Publications: Thousand Oaks, CA, USA, 2013.

26. Carter, G.; Smith, S.D. Safety Hazard Identification on Construction Projects. J. Constr. Eng. Manag. 2006, 132, 197-205. [CrossRef]

27. Nickles, G.M., III; Melloy, B.J.; Gramopadhye, A.K. A Comparison of Three Levels of Training Designed to Promote Systematic Search Behavior in Visual Inspection. Int. J. Ind. Ergon. 2003, 32, 331-339. [CrossRef]

28. Wang, M.J.; Lin, S.; Drury, C.G. Training for Strategy in Visual Search. Int. J. Ind. Ergon. 1997, 20, 101-108. [CrossRef]

29. Perlman, A.; Sacks, R.; Barak, R. Hazard Recognition and Risk Perception in Construction. Saf. Sci. 2014, 64, 22-31. [CrossRef]

30. Albert, A.; Hallowell, M.R.; Kleiner, B.M. Enhancing Construction Hazard Recognition and Communication with Energy-Based Cognitive Mnemonics and Safety Meeting Maturity Model: Multiple Baseline Study. J. Constr. Eng. Manag. 2014, 140, 04013042. [CrossRef] 
31. Fleming, M.; Fischer, B. Hazard Recognition: Bridging Knowledge \& Competency for Process \& Occupational Safety. Prof. Saf. 2017, 62, 52 .

32. Hallowell, M.R.; Hansen, D. Measuring and Improving Designer Hazard Recognition Skill: Critical Competency to Enable Prevention through Design. Saf. Sci. 2016, 82, 254-263. [CrossRef]

33. Haddon, W., Jr. Energy Damage and the Ten Countermeasure Strategies. Hum. Factors 1973, 15, 355-366. [CrossRef]

34. Jeelani, I.; Han, K.; Albert, A. Development of Virtual Reality and Stereo-Panoramic Environments for Construction Safety Training. Eng. Constr. Archit. Manag. 2020, 27, 1853-1876. [CrossRef]

35. Zhao, D.; Lucas, J. Virtual Reality Simulation for Construction Safety Promotion. Int. J. Inj. Control. Saf. Promot. 2015, $22,57-67$. [CrossRef]

36. Zhou, W.; Whyte, J.; Sacks, R. Construction Safety and Digital Design: A Review. Autom. Constr. 2012, 22, 102-111. [CrossRef]

37. Cherrett, T.; Wills, G.; Price, J.; Maynard, S.; Dror, I.E. Making Training More Cognitively Effective: Making Videos Interactive. Br. J. Educ. Technol. 2009, 40, 1124-1134. [CrossRef]

38. Evia, C. Localizing and Designing Computer-Based Safety Training Solutions for Hispanic Construction Workers. J. Constr. Eng. Manag. 2011, 137, 452-459. [CrossRef]

39. Goldenhar, L.M.; Moran, S.K.; Colligan, M. Health and Safety Training in a Sample of Open-Shop Construction Companies. J. Saf. Res. 2001, 32, 237-252. [CrossRef]

40. Gao, Y.; Gonzalez, V.A.; Yiu, T.W. The Effectiveness of Traditional Tools and Computer-Aided Technologies for Health and Safety Training in the Construction Sector: A Systematic Review. Comput. Educ. 2019, 138, 101-115. [CrossRef]

41. Han, Y.; Yin, Z.; Liu, J.; Jin, R.; Gidado, K.; Painting, N.; Yang, Y.; Yan, L. Defining and Testing a Safety Cognition Framework Incorporating Safety Hazard Perception. J. Constr. Eng. Manag. 2019, 145, 04019081. [CrossRef]

42. Choudhry, R.M. Behavior-Based Safety on Construction Sites: A Case Study. Accid. Anal. Prev. 2014, 70, 14-23. [CrossRef]

43. Cameron, I.; Duff, R. A Critical Review of Safety Initiatives using Goal Setting and Feedback. Constr. Manag. Econ. 2007, 25, 495-508. [CrossRef]

44. Vignoli, M.; Nielsen, K.; Guglielmi, D.; Mariani, M.G.; Patras, L.; Peiró, J.M. Design of a Safety Training Package for Migrant Workers in the Construction Industry. Saf. Sci. 2021, 136, 105124. [CrossRef]

45. Albert, A.; Jeelani, I.; Han, K. Developing Hazard Recognition Skill among the Next-Generation of Construction Professionals. Constr. Manag. Econ. 2020, 38, 1024-1039. [CrossRef]

46. Dzeng, R.; Lin, C.; Fang, Y. Using Eye-Tracker to Compare Search Patterns between Experienced and Novice Workers for Site Hazard Identification. Saf. Sci. 2016, 82, 56-67. [CrossRef]

47. Xu, Q.; Chong, H.; Liao, P. Exploring Eye-Tracking Searching Strategies for Construction Hazard Recognition in a Laboratory Scene. Saf. Sci. 2019, 120, 824-832. [CrossRef]

48. Perfect, T.J.; Schwartz, B.L. Applied Metacognition; Cambridge University Press: Cambridge, UK, 2002.

49. Tarricone, P. The Taxonomy of Metacognition; Psychology Press: Hove, UK, 2011.

50. Bannert, M.; Mengelkamp, C. Scaffolding hypermedia learning through metacognitive prompts. In International Handbook of Metacognition and Learning Technologies; Springer: Berlin/Heidelberg, Germany, 2013; pp. 171-186.

51. Berthold, K.; Nückles, M.; Renkl, A. Do Learning Protocols Support Learning Strategies and Outcomes? The Role of Cognitive and Metacognitive Prompts. Learn. Instr. 2007, 17, 564-577. [CrossRef]

52. Jeelani, I.; Albert, A.; Gambatese, J.A. Why do Construction Hazards Remain Unrecognized at the Work Interface? J. Constr. Eng. Manag. 2017, 143, 04016128. [CrossRef]

53. The National Institute for Occupational Safety and Health (NIOSH). Hierarchy of Controls. Available online: https:/ /www.cdc. gov/niosh/topics/hierarchy/default.html (accessed on 22 January 2021).

54. Greuter, S.; Tepe, S.; Peterson, J.F.; Boukamp, F.; d'Amazing, K.; Quigley, K.; van der Waerden, R.; Harris, T.; Goschnick, T.; Wakefield, R. Designing a Game for Occupational Health and Safety in the Construction Industry. In Proceedings of the 8th Australasian Conference on Interactive Entertainment: Playing the System, Auckland, New Zealand, 22 July 2012 ; pp. 1-8.

55. Albert, A.; Hallowel, M.R. Revamping Occupational Safety and Health Training: Integrating Andragogical Principles for the Adult Learner. Constr. Econ. Build. 2013, 13, 128-140. [CrossRef]

56. Kaskutas, V.; Dale, A.M.; Lipscomb, H.; Gaal, J.; Fuchs, M.; Evanoff, B. Changes in Fall Prevention Training for Apprentice Carpenters Based on a Comprehensive Needs Assessment. J. Saf. Res. 2010, 41, 221-227. [CrossRef]

57. Burke, M.J.; Sarpy, S.A.; Smith-Crowe, K.; Chan-Serafin, S.; Salvador, R.O.; Islam, G. Relative Effectiveness of Worker Safety and Health Training Methods. Am. J. Public Health 2006, 96, 315-324. [CrossRef]

58. Robson, L.S.; Stephenson, C.M.; Schulte, P.A.; Amick, B.C., III; Irvin, E.L.; Eggerth, D.E.; Chan, S.; Bielecky, A.R.; Wang, A.M.; Heidotting, T.L. A Systematic Review of the Effectiveness of Occupational Health and Safety Training. Scand. J. Work Env. Health 2012, 38, 193-208. [CrossRef]

59. Le, Q.T.; Pedro, A.; Park, C.S. A Social Virtual Reality Based Construction Safety Education System for Experiential Learning. J. Intell. Robot. Syst. 2015, 79, 487-506. [CrossRef]

60. Eggerth, D.E.; Keller, B.M.; Cunningham, T.R.; Flynn, M.A. Evaluation of Toolbox Safety Training in Construction: The Impact of Narratives. Am. J. Ind. Med. 2018, 61, 997-1004. [CrossRef]

61. Jeschke, K.C.; Kines, P.; Rasmussen, L.; Andersen, L.P.S.; Dyreborg, J.; Ajslev, J.; Kabel, A.; Jensen, E.; Andersen, L.L. Process Evaluation of a Toolbox-Training Program for Construction Foremen in Denmark. Saf. Sci. 2017, 94, 152-160. [CrossRef] 
62. Williams, Q., Jr.; Ochsner, M.; Marshall, E.; Kimmel, L.; Martino, C. The Impact of a Peer-Led Participatory Health and Safety Training Program for Latino Day Laborers in Construction. J. Saf. Res. 2010, 41, 253-261. [CrossRef]

63. Sandelands, E.; Sparks, A.; Ingram, H.; Phillips, S. Advanced Entry Adult Apprenticeship Training Scheme: A Case Study. Educ. Train. 2009, 51, 190-202.

64. Johari, S.; Jha, K.N. Development and implementation of on-the-job training system for construction workers. In Urbanization Challenges in Emerging Economies: Energy and Water Infrastructure; Transportation Infrastructure; and Planning and Financing; American Society of Civil Engineers: Reston, VA, USA, 2018; pp. 405-416.

65. Vermeulen, R.C. Narrowing the Transfer Gap: The Advantages of "as if" Situations in Training. J. Eur. Ind. Train. 2002, 26, 366-374. [CrossRef]

66. Kim, J.H.; Lee, C. Implications of Near and Far Transfer of Training on Structured on-the-Job Training. Adv. Dev. Hum. Resour. 2001, 3, 442-451. [CrossRef]

67. Hussain, R.; Pedro, A.; Lee, D.Y.; Pham, H.C.; Park, C.S. Impact of Safety Training and Interventions on Training-Transfer: Targeting Migrant Construction Workers. Int. J. Occup. Saf. Ergon. 2018, 26, 272-284. [CrossRef] [PubMed]

68. Prasad, R.; Feng, Y.; Hardy, M. Factors Influencing Safety Training Transfer on Construction Sites: A Literature Review. In Proceedings of the 21st International Symposium on Advancement of Construction Management and Real Estate, Gateway East, Singapore, 16 January 2018; pp. 759-768.

69. Chiaburu, D.S.; Dam, K.V.; Hutchins, H.M. Social Support in the Workplace and Training Transfer: A longitudinal Analysis. Int. J. Sel. Assess. 2010, 18, 187-200. [CrossRef]

70. Grossman, R.; Salas, E. The Transfer of Training: What really Matters. Int. J. Train. Dev. 2011, 15, 103-120. [CrossRef]

71. Galbraith, D.D.; Fouch, S.E. Principles of Adult Learning Application to Safety Training. Prof. Saf. 2007, 52, 35-40.

72. Knowles, M.S.; Holton, E.F., III; Swanson, R.A.; Robinson, P.A. The Adult Learner: The Definitive Classic in Adult Education and Human Resource Development. Ind. Commer. Train. 2020, 44, 438-439.

73. Reiman, A.; Airaksinen, O.; Väyrynen, S.; Aaltonen, M. HSEQ Training park in northern Finland-A novel innovation and forum for cooperation in the construction industry. In Integrated Occupational Safety and Health Management; Anonymous; Springer: Berlin/Heidelberg, Germany, 2015; pp. 145-153.

74. Reiman, A.; Møller Pedersen, L.; Väyrynen, S.; Airaksinen, O.; Sormunen, E.; Räsänen, T. Multi-Organisational Approach to Safety Training: The Case of a Finnish Safety Training Park. Constr. Manag. Econ. 2020, 38, 659-672. [CrossRef]

75. Guo, H.; Li, H.; Chan, G.; Skitmore, M. Using Game Technologies to Improve the Safety of Construction Plant Operations. Accid. Anal. Prev. 2012, 48, 204-213. [CrossRef]

76. Mohd, N.I.; Ali, K.N.; Bandi, S.; Ismail, F. Exploring Gamification Approach in Hazard Identification Training for Malaysian Construction Industry. Int. J. Built Environ. Sustain. 2019, 6, 51-57. [CrossRef]

77. Cerezo-Narváez, A.; Córdoba-Roldán, A.; Pastor-Fernández, A.; Aguayo-González, F.; Otero-Mateo, M.; Ballesteros-Pérez, P. Training Competences in Industrial Risk Prevention with Lego®Serious Play®: A Case Study. Safety 2019, 5, 81. [CrossRef]

78. Lin, K.; Son, J.W.; Rojas, E.M. A Pilot Study of a 3D Game Environment for Construction Safety Education. J. Inf. Technol. Constr. 2011, 16, 69-84.

79. Gao, Y.; González, V.A.; Yiu, T.W. Serious Games Vs. Traditional Tools in Construction Safety Training: A Review. LC3 2017, $1,4-7$.

80. Son, J.; Shin, S.; Yi, J. Application of Serious Games for Effective Construction Safety Training. Korean J. Constr. Eng. Manag. 2014, 15, 20-27. [CrossRef]

81. Din, Z.U.; Gibson, G.E., Jr. Serious Games for Learning Prevention through Design Concepts: An Experimental Study. Saf. Sci. 2019, 115, 176-187. [CrossRef]

82. Jeelani, I.; Han, K.; Albert, A. Automating and Scaling Personalized Safety Training using Eye-Tracking Data. Autom. Constr. 2018, 93, 63-77. [CrossRef]

83. Tang, N.; Hu, H.; Xu, F.; Zhu, F. Personalized Safety Instruction System for Construction Site Based on Internet Technology. Saf. Sci. 2019, 116, 161-169. [CrossRef]

84. Lu, M.; Hasan, M. Developing a Cost-Effective and Adaptive Training Program to Enhance Construction Safety in Tunneling Construction. In Proceedings of the Construction Research Congress, New Orleans, LA, USA, 2-4 April 2018; pp. 635-644.

85. Ho, C.; Dzeng, R. Construction Safety Training Via E-Learning: Learning Effectiveness and User Satisfaction. Comput. Educ. 2010, 55, 858-867. [CrossRef]

86. Clevenger, C.; Lopez del Puerto, C.; Glick, S. Interactive BIM-Enabled Safety Training Piloted in Construction Education. Adv. Eng. Educ. 2015, 4, 1-14.

87. Hall, A.K.; Nousiainen, M.T.; Campisi, P.; Dagnone, J.D.; Frank, J.R.; Kroeker, K.I.; Brzezina, S.; Purdy, E.; Oswald, A. Training Disrupted: Practical Tips for Supporting Competency-Based Medical Education during the COVID-19 Pandemic. Med. Teach. 2020, 42, 756-761. [CrossRef]

88. Aryal, A.; Parish, M.; Rohlman, D.S. Generalizability of Total Worker Health®Online Training for Young Workers. Int. J. Environ. Res. Public Health 2019, 16, 577. [CrossRef]

89. Occupational Safety and Health Administration. Outreach Training Program. Available online: https://www.osha.gov/dte/ outreach/construction/focus_four/ (accessed on 22 January 2021). 
90. Caban-Martinez, A.J.; Santiago, K.M.; Stillman, J.; Moore, K.J.; Sierra, D.; Chalmers, J.; Baniak, M.; Jordan, M.M. Physical Exposures, Work Tasks and OSHA-10 Training among Temporary and Payroll Construction Workers. J. Occup. Environ. Med. 2018, 60, e159. [CrossRef] [PubMed]

91. Taylor, E.L. Safety Benefits of Mandatory OSHA 10 H Training. Saf. Sci. 2015, 77, 66-71. [CrossRef]

92. Ruttenberg, R. The Economic and Social Benefits of OSHA-10 Training in the Building and Construction Trades; Center for Construction Research and Training (CPWR): Silver Spring, MD, USA, 2013.

93. O'Connor, T.; Flynn, M.; Weinstock, D.; Zanoni, J. Occupational Safety and Health Education and Training for Underserved Populations. New Solut. A J. Environ. Occup. Health Policy 2014, 24, 83-106. [CrossRef] [PubMed]

94. Ricci, F.; Chiesi, A.; Bisio, C.; Panari, C.; Pelosi, A. Effectiveness of Occupational Health and Safety Training. J. Workplace Learn. 2016, 28, 355-377. [CrossRef]

95. Sinyai, C.; Stafford, P.; Trahan, C. Doing it Old School: Peer-Led Occupational Safety Training in the US Construction Industry. Mcgill J. Educ. Rev. Des. Sci. De L'éducation De Mcgill 2013, 48, 605-611. [CrossRef]

96. De Souza, R.A.; Hecker, S.; De Castro, A.B.; Stern, H.; Hernandez, A.; Seixas, N. Novel Approaches to Development, Delivery and Evaluation of a Peer-Led Occupational Safety Training for Latino Day Laborers. N. Solut. A J. Environ. Occup. Health Policy 2012, 22, 387-405. [CrossRef]

97. Menzel, N.N.; Shrestha, P.P. Social Marketing to Plan a Fall Prevention Program for Latino Construction Workers. Am. J. Ind. Med. 2012, 55, 729-735. [CrossRef] [PubMed]

98. Lingard, H.; Pink, S.; Harley, J.; Edirisinghe, R. Looking and Learning: Using Participatory Video to Improve Health and Safety in the Construction Industry. Constr. Manag. Econ. 2015, 33, 740-751. [CrossRef]

99. Sekerin, V.D.; Gaisina, L.M.; Shutov, N.V.; Abdrakhmanov, N.K.; Valitova, N.E. Improving the Quality of Competence-Oriented Training of Personnel at Industrial Enterprises. Calitatea 2018, 19, 68-72.

100. Choi, B.; Ahn, S.; Lee, S. Role of Social Norms and Social Identifications in Safety Behavior of Construction Workers. I: Theoretical Model of Safety Behavior Under Social Influence. J. Constr. Eng. Manag. 2017, 143, 04016124. [CrossRef]

101. Pandit, B.; Albert, A.; Patil, Y. Developing Construction Hazard Recognition Skill: Leveraging Safety Climate and Social Network Safety Communication Patterns. Constr. Manag. Econ. 2020, 38, 640-658. [CrossRef]

102. Collin, K. Work-related Identity in Individual and Social Learning at Work. J. Workplace Learn. 2009, 21, 23-35. [CrossRef] 